Nota crítica / Essay

\title{
EL COVID-19 Y EL TURISMO RURAL: UNA PERSPECTIVA ANTROPOLÓGICA
}

\author{
MAXIMILIANO E. KORSTANJE \\ mkorst@palermo.edu \\ Universidad de Palermo, Argentina
}

La ruralidad juega un rol importante en la historia del turismo en América Latina, con un lugar dentro del colectivo imaginario de las grandes urbes. El sistema capitalista ha forzado la migración masiva de las zonas rurales, las cuales quedaron despobladas, a las grandes ciudades. Hoy, el turismo rural ofrece un escape para miles de turistas citadinos y una oportunidad para las economías domésticas. En momentos de crisis como aquella que ha suscitado el COVID-19, se presenta como un destino obligado para miles de personas, como alternativa válida a una nueva normalidad donde el encuentro con el otro se encuentra clausurado. La pandemia no solo ha acelerado una crisis de sentido en el mundo occidental, probablemente causada por el 11 de septiembre, sino que reafirma una tendencia a la cual hemos Ilamado "la muerte de la hospitalidad". En los días sucesivos al 9/11 muchos americanos elegían destinos rurales para sus vacaciones, por ello, no sorprende notar que la mayoría de los abordajes empíricos y teóricos se remontan a los años sucesivos al 2001. Estos estudios arrojan cierta luz sobre los efectos positivos y negativos alrededor del turismo rural que, como se ha discutido en la presente pieza de revisión crítica, parece no ser la solución a todos los problemas.

Palabras clave: turismo rural, COVID-19, hospitalidad, otredad.

\section{COVID-19 AND RURAL TOURISM: AN ANTHROPOLOGICAL PERSPECTIVE}

Rurality plays an important role in the history of tourism in Latin America, it occupies a place within the imaginary collective of large cities. The capitalist system has forced massive migration from these areas, which were left unpopulated, to the big cities. Today, rural tourism offers an escape for thousands of city tourists and an opportunity for domestic economies. In times of crisis like the one that has caused COVID-19, is presented as a must-see destination for thousands of people as a valid alternative to a new normal where the encounter with the other is closed. The pandemic has not only accelerated a crisis of meaning in the Western world, probably caused by September 11th, but it also reaffirms a trend that we have called "the death of hospitality." In the days after 9/11, many Americans chose rural destinations for their vacations, therefore it is not surprising to note that most of the empirical and theoretical approaches date back to the years after 2001. These studies shed some light on the positive and negative effects around rural tourism that, as discussed in this critical review piece, appears not to be the solution to all problems.

Keywords: Rural tourism, COVID-19, hospitality, otherness.

Fecha de recepción: 15 de julio de 2020

Fecha de aceptación: 25 de julio de 2020

CÓMO CITAR: Korstanje, M. E. (2020) El COVID-19 y el turismo rural: una perspectiva antropológica. Dimensiones Turísticas [Número especial: Turismo y COVID-19], 4, 179-196. https://doi.org/10.47557/CKDK5549 


\section{Introducción}

A fines de diciembre de 2019, el mundo quedaba consternado respecto a las noticias que llegaban de la ciudad de Wuhan, China, respecto a un nuevo coronavirus (CO-SARSv2) conocido como COVID-19. Pronto, el virus se diseminó por el mundo afectando las economías y los sistemas sanitarios de los principales países del mundo, y paralizó literalmente al planeta. En la actualidad, el COVID-19 se ha llevado la vida de 844 mil 173 personas, a la vez que infectó a más de 25 millones en todo el mundo. Entre las naciones con mayor cantidad de fallecidos se presentan los Estados Unidos (186 mil 382), seguido por Brasil (120 mil 025), India (63 mil 631), Reino Unido (41 mil 498), Francia (30 mil 602), España (29 mil 011) y Perú (28 mil 471) por nombrar algunos.

Estos números, vigentes al 29 de agosto de 2020, se encuentran en constante ascenso. Por lo pronto, los países han adoptado dos tipos de estrategias claras y distintas. Por un lado, aquellos países que adoptaron cuarentenas (lockdown) estrictas, las cuales implicaron el cierre de fronteras, espacios aéreos, escuelas y oficinas públicas o toques de queda. Por el otro, aquellos en los cuales el aislamiento ha tomado un matiz voluntario u optativo. Cualquiera sea el caso, el avance del COVID-19 ha modificado el estilo de vida en las diferentes ciudades del mundo, además de afectar seriamente a la industria turística.

Christopher Gaffney y Bruno Eeckels (2020) sostienen que la alta movilidad asumida por el turismo ha sido la causa central de la diseminación del virus; sin embargo, al mismo tiempo, fue la válvula a la cual los diferentes gobiernos apelaron para detenerla. Los autores señalan que los impactos fueron particularmente diferentes en las economías del primero y el tercer mundo; sin embargo, advierten, en común los países dependientes del turismo y de su factor de multiplicación de empleos son aquellos más sensibles a los efectos del COVID-19. Habiendo dicho eso, los investigadores comenzaron a discutir críticamente los alcances de la pandemia, evaluando y diagnosticando el futuro de la actividad para las próximas décadas.

Si bien se ha escrito y publicado mucho sobre el tema, los estudios carecen de una base empírica solida. Como advierte Adrian Franklin (2007), la teoría económico-céntrica del turismo ha puesto demasiada atención a la voz del turista como único interlocutor válido con el investigador. El turista es, a razón de esta lógica, no solo el objeto de estudio predilecto de los investigadores, sino el engranaje más importante del sistema turístico. 
En un mundo sin turistas, el paradigma económico-céntrico muestra serias fallas epistemológicas y metodológicas para presentar avances en materia de investigación aplicada. No obstante, las publicaciones en la materia pueden clasificarse en dos familias claramente identificadas: a) aquellas teorías que hacen foco en los efectos del COVID-19 y la necesidad de adoptar medidas de mayor sustentabilidad para regular la actividad (Gallego y Font, 2020; Carr, 2020; Gössling et al., 2020; Higgins-Desbiolles, 2020a), y b) aquellas orientadas a discutir puntos metodológicos en vista de las nuevas tecnologías disponibles (Wen et al., 2020; Sigala, 2020).

Otros autores han esgrimido la tesis de que el COVID-19 cierra una crisis de sentido para Occidente, que termina con la muerte o el declive de la hospitalidad (Romagosa, 2020; Korstanje, 2020a, 2020b). Cabe preguntarse si ¿es el COVID-19 el principio o, por el contrario, el fin del turismo clásico?

En la presente nota crítica se establece un eje discursivo que intenta discutir las consecuencias de la pandemia, en el escenario de la ruralidad y el turismo creativo.

\section{El COVID-19 y el turismo}

La historia de los virus y el turismo se encuentra lejos de ser novedosa, diversos virus han afectado a la humanidad por años. Por supuesto, el sector turístico no es una excepción. Desde 2001, diversos brotes han sacudido a la industria del turismo y la hospitalidad. Los turistas, por regla general, buscan destinos seguros y evitan aquellos que son percibidos como peligrosos. Lo que escapa al control visual, como la enfermedad o un virus, representa un desafío a la lógica racional (Sunstein, 2005). En un mundo que tiene que ver para creer (ocularcentrismo), los riesgos invisibles revisten un impacto mayor en el imaginario colectivo, en comparación con aquellos que se pueden prever (Hall et al., 2004; Brouder et al., 2020; Tarlow, 2014).

En perspectiva, tanto en el H1N1, como en el Síndrome Respiratorio Agudo Grave (SARS), Síndrome respiratorio de Oriente Medio (MERS) o Ébola, las medidas restrictivas de los gobiernos fueron más o menos similares, comprendiendo el cierre de fronteras, la suspensión de ciertos derechos de movilidad, y el control férreo de los medios de transporte. Sin miedo al error, se puede agregar que el turismo y la alta movilidad del mundo capitalista, asociado a las grandes urbanizaciones, son un campo propicio para la rápida expansión de una enfermedad (McKercher y Chon, 2004; Monterrubio, 2010; Solarin, 2015; Novelli et al., 2018). 
La ansiedad que despierta vivir en un mundo más volátil y fluido modela el sentir de un imaginario colectivo occidental, que vincula la enfermedad con aquello que es naturalmente maligno. En películas como Contagio, por ejemplo, un virus -casi siempre originado en Asia por supuestas condiciones de falta de higiene- llega a un prístino mundo occidental, invitado por la industria del turismo y los viajes. Más allá de los discursos ideológicos sobre cómo el occidente clasifica e intenta domesticar a oriente, todo viaje despierta miedos y ansiedades debido a un encuentro con ese Otro diferente, el cual nos interpela como sociedad.

La idea de viajar implica una salida a un destino incierto, con costumbres nuevas, y bajo condiciones que escapan a nuestro control (Korstanje, 2018). En términos de Jacques Derrida (2000), la hospitalidad puede brindarse, o no, pero lo más importante es que el extranjero es aquel que interpela el dogmatismo de nuestro sistema de creencias, y al hacerlo pone en jaque al lenguaje. En esta misma línea, Daniel Innerarity (2017) sostiene que la hospitalidad se centra en la premisa de respeto por el huésped, incluso cuando este no tenga recursos económicos para ofrecer en contraprestación. Cerrarse al Otro es una invitación a la aniquilación cultural de una sociedad. En este sentido, el COVID-19 y la clausura del festejo primigenio (las festividades, el ocio y las experiencias oníricas) generan un debilitamiento de los lazos sociales y de la hospitalidad (Korstanje 2020a).

Si para la inteligencia europea y colonial, el Otro nativo era considerado como un niño desprovisto de razón, el cual, dadas ciertas condiciones, podía ser reeducado bajo los valores culturales de la llustración, en la actualidad ese Otro es un agente de temor, negado y relegado a la sensación de un peligro extremo (Korstanje, 2020a). La figura del terrorista, que se inaugura el 11 de septiembre como alguien que puede atacar en cualquier momento, cede paso a un virus que se esconde en cada uno de nosotros. El terrorista no es maligno por sus actos, sino que, teniendo las posibilidades de vivir y ser como un occidental, elige lo opuesto. El 9/11 establece una nueva lógica del miedo donde el enemigo vive dentro, luce como nosotros $y$, lo que es peor, puede atacar en cualquier momento.

Una revisión del argumento en una docena de películas de terror modernas sugiere que el arquetipo del villano ha cambiado a una forma más radicalizada. El huésped, por lo general joven y lleno de proyectos, es invitado a un banquete; el anfitrión, quien no revela sus verdaderas intenciones, captura al huésped cuando duerme para torturarlo o asesinarlo. Esta lógica emergente del mal se inscribe en una cul- 
tura de la securitización ${ }^{1}$ producto del 11 de septiembre (Korstanje y Olsen, 2011; Korstanje y Tarlow, 2012).

El terrorismo clausura la hospitalidad, minando a Occidente por dentro. Lo manifiesto y lo oculto se desdibujan a raíz de un sentimiento de temor y desconfianza, donde todos somos potenciales terroristas. Ahora bien, si el agresor, considerado un nativo de las sociedades a las cuales ataca, opera dentro del miedo que supone la idea "del enemigo dentro" (the evil inside), el COVID-19 confirma la misma tendencia, pero en este caso todas las personas son potenciales armas biológicas.

Diversos estudios demuestran que en momentos de incertidumbre y crisis (como en los días posteriores al 9/11), los flujos turísticos no desaparecen, sino que mutan y se dirigen hacia zonas rurales, comúnmente alejadas de la ciudad. El turismo rural es, en vista de ello, un segmento sustituto del turismo urbano o masivo en momentos difíciles (Bhattarai et al., 2005; Drakos y Kutan, 2003; Yuan, 2005). El estado de emergencia creado por el COVID-19 cercena los derechos individuales a la libre movilidad, situación que se asemeja con el terrorismo, y demuestra las asimetrías materiales entre las clases sociales.

Zygmunt Bauman argumenta que el mundo móvil lo es solo para algunos elegidos, mientras una gran cantidad de personas se mantiene inerte, o son perseguidos cuando emigran a otros países. La figura del vagabundo, el cual es un agente itinerante temido por la cultura del consumo, se contrapone al turista como eje civilizador de la cultura occidental (Bauman 2017). De la misma premisa parten Thomas Baum y Nguyen Thi Thanh Hai (2020) quienes ponen en cuestionamiento la idea de concebir al turismo como un derecho inalienable, o un derecho humano básico, comparable a la alimentación y/o acceso a la educación. La pandemia pone de manifiesto una suspensión temporal de los derechos individuales, confinando a las personas a su ámbito de residencia.

Si el capitalismo global incentiva a viajar libremente, aceptando el principio de libre tránsito como su valor cultural fundante, en el contexto pos-COVID-19, se regulan y aplican serias penalidades económicas para aquellos que, en su decisión de viajar, violan el aislamiento social y obligatorio. Los desafíos sobre el derecho de viajar son una parte importante de las preocupaciones de los ciudadanos del primer mundo,

1 En 1995, Ole Waever acuñó el término securitización (securitization) como una reacción a los estudios tradicionales sobre seguridad, a las teorías realistas y neorrealistas de la disciplina de las relaciones internacionales, que restringían el concepto de "amenazas" solamente a peligros de tipo militar, generalmente entre Estados. 
incluso motivo de reclamo y protesta, pero se encuentran lejos de ser una preocupación para los del tercer mundo, la mayoría imposibilitados de tal derecho.

Lo que es igualmente importante, más allá del tema ecológico, es que el COVID-19 permite reconstruir y disputar las antiguas ataduras y discursos dominantes, entre un centro colonial e imperial y la periferia colonizada en siglos anteriores. Se da en este sentido una casual paradoja, ya que los medios de producción técnicos, que han legitimado la expansión colonial europea y capitalista, son los mismos que generan los puentes de acceso al COVID-19. La periferia, empobrecida por las inequidades de la relación con los países imperiales, es ahora menos sensible a las medidas restrictivas a la movilidad; mientras que el norte global, que se benefició económicamente de dicha relación, es hoy víctima de las consecuencias de la pandemia en sus respectivas sociedades.

La crisis económica que deja la pandemia permite la reconfiguración de una nueva modalidad de turismo, constituido por el bien colectivo y no por el hiperconsumismo solipsista. En otras palabras, el sentido de vivir bien o de bienestar debe reemplazar a la rentabilidad (Sheller, 2020; Everingham y Chassagne, 2020). En ese sentido, Mimi Sheller (2020) acuña el término -problemático- mobility justice (movilidad justa), para explicar las escalas y posibles campos de acción que ayudan a mitigar los efectos negativos de una estructura social centrada en la injusticia social. Desequilibrios forjados en una era colonial, donde el paradigma europeo domesticó y subordinó al Otro diferente.

Por lo anterior, se asume que diversos nuevos segmentos tienden o tenderán a desplazarse hacia zonas de ruralidad, o lo que Scott Lash y John Urry (1993) llaman wild spaces (espacios salvajes). Los autores sugieren que el sistema capitalista se ha cristalizado gracias a dos variables importantes: la primera es la regulación de las transacciones por medio de un signo, los productos no se consumen a raíz de satisfacer una necesidad real, sino simbólica y ficticia. La segunda variable es una economía global y descentralizada, que sienta las bases para la creación de una matriz que divide el mundo en dos: el mundo apolíneo y civilizado, y las zonas salvajes a las cuales nadie quiere viajar.

En esta sociedad global, lo que se disfruta por medio de la vista se posee. El turismo moderno mercantiliza no solo relaciones humanas sino culturas, costumbres y personas (Lash y Urry, 1993). Siguiendo este razonamiento, el turismo rural o creativo ofrecería una alternativa a un nuevo proceso o nueva normalidad, implicando un cambio sustancial hacia una desmercantilización del "Otro no-occidental". 


\section{Lo rural como espacio de encuentro}

En su libro Imperial Eyes (Ojos Imperiales), Louis Marie Pratt (2007) se remonta a la necesidad de la ciencia de catalogar y clasificar el mundo sensible como la base angular de la cultura moderna y occidental. Al "hacer", la idea de estar-ahí cobra protagonismo y permite la marcación de diferentes etnias, o grupos étnicos ajenos a la cultura europea. Viajar, en este sentido, alimenta una nueva cultura de entretenimiento orientada principalmente a un lector versado e interesado por la diferencia, la llamada novela de viajes. Este nuevo dispositivo ideológico permite legitimar la conquista colonial a la vez que impone a ese Otro la necesidad de occidentalizarse. Como Adán en el paraíso, la novela inviste a los viajeros europeos del derecho de objetividad y todo lo que observan como regla sagrada de la ciencia. Es así como, marcando al diferente, el europeo evita ser marcado.

Ese Otro "no europeo" queda desprovisto de voz propia, marginalizado y presionado a ser reconstruido acorde a una matriz imperial que es inexpugnable. Pratt (2007) reconoce que consumir novelas de viajes es un acto de autoafirmación doble: por un lado, confirma la necesidad de civilizar y, por el otro, asume que la cultura europea es la fase civilizatoria más avanzada de la humanidad. En este sentido, si el paternalismo europeo reconoce la necesidad de reeducar y proteger al nativo, ciertamente al hacerlo asume su inferioridad. De la misma manera que las formas culturales premodernas en Europa desaparecieron tras el advenimiento del industrialismo, de la misma forma el mundo indígena desaparecerá.

El paternalismo europeo se encuentra imposibilitado de resolver la paradoja de la hospitalidad, donde el encuentro entre huésped y anfitrión se subvierte en un espacio vacío y de canibalización (MacCannell, 1992; Augé, 1998; Palmer y Lester, 2007; Tzanelli, 2004, 2008; Korstanje, 2018; Morrow y Shields, 2019). Como bien argumenta Rodanthi Tzanelli (2013), la mirada turística (tourist gaze) permite una articulación ideológica y estructural que reproduce y fabrica escenarios fantásticos, donde la historia se cuenta y se impone, siguiendo los parámetros de superioridad cultural europea.

En esa construcción, el nativo asume su supuesta inferioridad por medio de narrativas forjadas fuera de su cosmología, su posibilidad de comprender el mundo que le rodea. La curiosidad por el sufrimiento, que es propia del primer mundo, nunca asume la crueldad y la violencia que los estados europeos han ejercido sobre sus colonias en el pasado (Tzanelli 2013). El mal llamado turismo indígena o cultural, 
como ha sido discutido por M. Korstanje (2018, 2020a, 2020b), busca proteger al nativo por medio del cultivo de la curiosidad por sus costumbres; sin embargo, lejos de considerarlo un igual, lo subsumen como un commodity o bien mercantil.

Un ejemplo nos ayudará a comprender mejor cómo funciona este dispositivo narrativo: si un nativo Sioux viaja a Chicago, lo más factible es que el viaje sea catalogado como un viaje turístico. No obstante, si un ciudadano de Nueva York viaja a una reserva Sioux, ese viaje sería considerado "étnico" o inherente al turismo indígena. Como Korstanje infiere, la etiqueta impuesta por el marcador domina más por lo que calla que por lo que dice $y$, al hacerlo, el dominador evitar ser nomenclado.

El turismo cultural y la tendencia a la patrimonización sustentan el mismo paternalismo europeo del régimen colonial, continúa su esencia y con ella la dependencia de la periferia respecto a un centro siempre idealizado (Korstanje, 2012). Sin miedo al error, cabe agregar que el turismo rural, creativo o cultural corre los mismos riesgos de mercantilizar al Otro que el turismo masivo.

En la próxima sección se discuten los beneficios, problemas y desafíos de este tipo de turismo en tiempos de COVID-19.

\section{Desafíos y problemas del turismo rural}

Como se ha mencionado, lo rural se sitúa como alternativa cuando la idea de lo urbano es sinónimo de peligro. Los turistas, en la mayoría de los casos, buscan sitios apacibles, confortables, donde su seguridad ontológica no se encuentre en juego. La seguridad del turista es una pieza fundamental de la investigación en el sector. Durante años los investigadores asumieron la creencia de que la demanda turística asume una naturaleza totalmente retráctil al riesgo interno o externo; en otras palabras, en momentos de tensión o peligro el destino turístico se paraliza. Por el contrario, las últimas investigaciones demuestran que el turismo, lejos de desaparecer, cambia sus flujos hacia otros destinos.

Cuando el evento disruptivo tiene como escenario el paisaje urbano, el sistema distribuye sus flujos hacia lo rural (Saha y Yap, 2014; Bassil, 2014; Korstanje y Clayton, 2012; Tarlow, 2014). Sanjay Nepal (2020) afirma que existe un particular interés por el turismo en aéreas naturales lo cual significa que el turismo experimente una 
suerte de "refundación" (reset). Las actividades al aire libre parecen ser preferibles a los tours urbanos en muchas partes del mundo todavía prohibidos.

Lo rural y el turismo de aventura son dos segmentos que se ven beneficiados por las restricciones impuestas en contextos del COVID-19. Mismas conclusiones pueden verse en otros abordajes como Buckley (2020), Higgins-Desbiolles (2020a, 2020b), Stankov et al., 2020) y Carr (2020), entre otros. En este sentido surge un interrogante: ¿Es todo turismo creativo, rural? y viceversa ¿es todo turismo rural, en esencia, creativo?

La literatura define al turismo rural como aquel que permite, promueve y promociona una participación en cualquier esfera de la vida campestre. Si bien algunos lo confunden con el turismo sustentable, existe una relación directa con el interés ecológico y la agricultura, sobre todo en segmentos de turistas provenientes de centros de alta concentración urbana (Lane 1994; Bramwell, 1994; Wilson et al., 2001).

El turismo creativo, no necesariamente se vincula a lo rural, aun cuando puede ser un aspecto importante del mismo. El turismo creativo, entonces, es aquel que ofrece el potencial para crear un objeto, el cual es producto de la participación colaborativa entre huésped y anfitrión. En el turismo creativo, no hace falta "estar-ahí" simulando vivir como el nativo, sino simplemente trabajar al lado de él, en la expectativa de un producto en común (Richards y Raymond, 2000; Tan et al., 2014; Marques y Borba, 2017).

El turismo creativo, por su apego a una experiencia individual y relacional, impide la reproducción masiva en la cual cayeron otras tendencias. Cada experiencia es única por definición, ya que es la misma persona (turista) la responsable de la cocreación. El turismo creativo aplicado en ciudades puede desarrollar personalidades más abiertas y democráticas (Den Dekker y Tabbers, 2012). Uno de los aspectos a tener en cuenta, como limitación del turismo rural y creativo, se asocia a lo que Greg Richards (2011) llama paradoja de la comoditización, la cual asume que una porción cada vez mayor de turistas se ven seducidos por esta clase de destinos, en parte porque representa una experiencia única y también debido a su naturaleza relacional. Como resultado, el turismo creativo experimenta los mismos problemas que el turismo clásico, pues se tiende a una concentración de las prácticas en el territorio.

Cada vez, y de forma progresiva, una cantidad más grande de turistas se desplazan a aéreas rurales en búsqueda de esta clase de experiencias, comenzando un proceso de reproducción mecánica y estandarizada del consumo turístico, debido a 
la imposibilidad de cambiar los valores fundantes del capitalismo (Richards, 2011). En un texto ya clásico, Richard Sharpley (2002) nos recuerda que, si bien el turismo rural ayuda al crecimiento económico a largo plazo, en el mediano se requieren volúmenes de capital y financiación a los cuales no siempre se puede acceder.

En países en vías de desarrollo, donde la economía es dependiente del turismo, el turismo rural se asocia a efectos negativos como desempleo, migración forzada, y especulación financiera. Es importante entender que este tipo de actividad turística no es la solución única a todos los problemas de las economías rurales. Mitchell y Hall (2005) explican que, en su génesis, el turismo rural evoluciona acorde a una pobre planificación o al desconocimiento de ciertas cuestiones de mercado que, indudablemente, afectan al prestador de servicios. Se tiene la idea equivocada de que el turismo rural no solo potencia aquellas economías que sufren crisis temporales, sino que muchas veces el mismo destruye el potencial agrario de un destino.

La industria agraria se encuentra sujeta a diferentes riesgos y condiciones que van desde los problemas climáticos hasta los precios internacionales de commodities. El turismo rural puede ayudar a mitigar los efectos adversos de las crisis, pero en otras ocasiones puede incluso agravarlos. Los autores enfatizan que, en un mundo globalizado y altamente tecnologizado, es necesario estudiar cómo el mercado del turismo rural puede adaptarse a un consumidor global, cuyos gustos y tendencias podrían erosionar las propias costumbres de los pobladores locales.

Por su parte, Dallen Timothy (2005) no se equivoca al remarcar que el capitalismo industrial ha despoblado las grandes zonas rurales en Europa y América, forzando a una migración de trabajadores del campo a la ciudad. Dicha tendencia ha saturado las grandes ciudades; en la actualidad miles de personas buscan en lo rural una suerte de escape. La vida en la ciudad es vista como necesaria pero tediosa y peligrosa a la vez. Lo rural ofrece un paisaje prístino donde el self puede distanciarse de las obligaciones cotidianas.

Miles de estadounidenses eligen hoy las reservas indígenas, cita Timothy (2005), para pasar parte de sus vacaciones o estadías de corta duración. La industria del casino en estas reservas establece una dinámica interna de competencia y conflictos domésticos, por imponer la marca de la reserva. Siguiendo esta misma línea, Nylander y Hall (2005) advierten que una de las paradojas del turismo rural versa en la competencia del propio mercado. 
En un estadio inicial, el turismo rural es usado como instrumento potenciador del destino, a través de la protección de su imagen. Por tal motivo, se utilizan sofisticadas técnicas de mercadeo y management aumentando la interacción con otros actores y procesos. A medida que la competencia se acrecienta, mayores son los riesgos y el diálogo entre los diferentes componentes del sistema. Los turistas que demandan esta clase de sitios son citadinos o viven en grandes ciudades. Adaptar la infraestructura del destino a sus gustos implica una importación de bienes y costumbres que generan un proceso de aculturación, a la par que los destinos con mayores niveles de inversión de capital puedan sobrevivir.

En efecto, el mercado del turismo rural se encuentra altamente concentrado en pocos oferentes. A eso se le suma otro problema, el cual subyace en que el turista rural se mueve en un ambiente de cambio constante, en donde sus necesidades se reciclan en forma frecuente. Una demanda cambiante, asociada a una saturación del mercado por acumulación de firmas, Ilevan a Nylander y Hall a señalar que el turismo rural no parece ser una solución mágica para todos los problemas. Asimismo, en su libro Ethnicity Inc, Comaroff y Comaroff (2009) Ilaman la atención sobre los peligros del turismo aplicado a ciertos contextos de conflicto étnico. Ciertos grupos, los cuales han sido relegados por el estado nacional del sistema productivo, pueden acceder a los beneficios de explotación que ofrece el turismo.

En reservas aborígenes de Estados Unidos o África, el turismo étnico promueve el consumo en economías totalmente estancadas o relegadas a una situación periférica, respecto al mercado del turismo urbano. No obstante, cuando los gobiernos centrales intentan gravar los nuevos emprendimientos hoteleros y de turismo, se da una serie de reacciones hostiles que, en mayor o menor medida, pueden terminar con una situación violenta, sobre todo en el caso africano, donde ciertas etnias antagónicas han tomado el control del poder ejecutivo.

Lo que el libro sugiere es que es imposible cambiar las inequidades de un sistema, si no se cambian los valores que le dieron origen. En otras palabras, las asimetrías materiales del capitalismo son producto de un valor específico orientado a la acumulación de capital. Cuando se adopta al turismo para paliar los efectos nefastos de la pobreza, pero no se atiende a la causa estructural que la genera, se corre el riesgo de mercantilizar la necesidad. En consecuencia, el turismo se transforma en un instrumento que a largo plazo genera las mismas patologías sociales que intenta combatir. Bianca Freire Medeiros (2014) hace una llamada a repensar el tema del 
turismo en villas de emergencias (slum-tourism) sin mercantilizar a la pobreza como commodity de intercambio. Si se parte de la base de que la pobreza es una atracción, todo indica que el sistema tenderá a replicarla para ser consumida por otros.

\section{Conclusiones}

Existe una tensión necesaria entre ciudad y campo. En su naturaleza, la ruralidad juega un rol importante en la historia del turismo en América Latina (Schlüter, 2003). Como un continuum que demarca el pasaje de lo cotidiano a lo extraordinario (MacCannell 1976), la ruralidad ocupa un lugar de peso dentro del colectivo imaginario de las grandes urbes. El sistema capitalista ha forzado la migración masiva de las zonas rurales, quedando despobladas, a las grandes ciudades (Mair et al., 2005).

En la actualidad, el turismo rural brinda una salida o escape para miles de turistas citadinos y una oportunidad para revitalizar -o recuperar- las economías domésticas de la crisis que deja el COVID-19. En momentos de incertidumbre, como los que ha suscitado la pandemia, el turismo rural se presenta como un destino obligado para miles de personas. Para citar un ejemplo, en la televisión argentina y mundial, muchos programas dedicados a los viajes internacionales presentan hoy al turismo rural o de estancia como alternativas válidas a una nueva normalidad, donde el encuentro con el Otro se encuentra clausurado.

El COVID-19 no solo ha acelerado una crisis de sentido en el mundo occidental, probablemente causado por el 11 de septiembre, sino que reafirma una tendencia a la cual hemos llamado "la muerte de la hospitalidad". En los días sucesivos al 9/11, muchos estadounidenses optaban por destinos rurales para sus vacaciones. Ante la desconfianza en lo "urbano", el turismo rural se situaba como un segmento prometedor a la vez que misterioso (Korstanje, 2018). No sorprende notar que la mayoría de los abordajes empíricos y teóricos sobre el tema se remontan a los años sucesivos al 2001.

En perspectiva, dichos estudios han arrojado cierta luz sobre los efectos positivos, pero también de los negativos alrededor del turismo rural. Empero, a diferencia de 2001, en la actualidad se observa una "refeudalización del mundo" donde los límites clásicos se desdibujan y desaparecen. Sobran los ejemplos de pequeñas ciudades que se han blindado frente a la entrada de personas de otras ciudades, o han establecido medidas de control al tráfico, lo que viola el derecho constitucional al libre tránsito. 
El COVID-19 marca un fin de ciclo donde la ley sacra de hospitalidad queda suspendida. Como se ha discutido en la presente pieza de revisión crítica, el turismo rural parece no ser la solución a todos los problemas del sector, sobre todo cuando existe un divorcio entre la ética y la planificación responsable. El tiempo dirá si el auge del turismo rural en tiempos de pandemia es el signo de una nueva forma de turismo (capitalismo) o su reafirmación.

\section{Referencias}

Augé, M. (1998). El viaje imposible: el turismo y sus imágenes. Editorial Gedisa.

Bassil, C. (2014). The effect of terrorism on tourism demand in the Middle East. Peace Economics, Peace Science and Public Policy, 20(4), 669-684. https://doi. org/10.1515/peps-2014-0032

Baum, T. y Hai, N. T. T. (2020). Hospitality, tourism, human rights and the impact of COVID-19. International Journal of Contemporary Hospitality Management. 32(7): 2397-2407. https://doi.org/10.1108/JJCHM-03-2020-0242

Bauman, Z. (2017). Tourists and vagabonds: or, living in postmodern times. En Identity and social change (pp. 19-32). Routledge.

Bhattarai, K., Conway, D. y Shrestha, N. (2005). Tourism, terrorism and turmoil in Nepal. Annals of Tourism Research, 32(3), 669-688. https://doi.org/10.1016/j.annals.2004.08.007

Bramwell, B. (1994). Rural tourism and sustainable rural tourism. Journal of Sustainable Tourism, 2(1-2), 1-6. https://doi.org/10.1080/09669589409510679

Brouder, P., Teoh, S., Salazar, N. B., Mostafanezhad, M., Pung, J. M., Lapointe, D., Higgins-Desbiolles, F., Haywood, M., Hall, C. M. y Clausen, H. B (2020). Reflections and discussions: tourism matters in the new normal post COVID-19. Tourism Geographies, 1-12. https://doi.org/10.1080/14616688.2020.1770325

Buckley, R. (2020). Pandemic travel restrictions provide a test of net ecological effects of ecotourism and new research opportunities. Journal of Travel Research, 00, 1-3. https://doi.org/10.1177/0047287520947812 
Carr, A. (2020). COVID-19, indigenous peoples and tourism: a view from New Zealand. Tourism Geographies, 1-12. https://doi.org/10.1080/14616688.2020 .1768433

Comaroff, J. L. y Comaroff, J. (2009). Ethnicity, Inc. University of Chicago Press.

Den Dekker, T. y Tabbers, M. (2012). From creative crowds to creative tourism: a search for creative tourism in small and medium size cities. Journal of Tourism Consumption and Practice, 4(1), 129-141.

Derrida, J. y Dufourmantelle, A. (2000). Of hospitality. Stanford University Press.

Drakos, K. y Kutan, A. M. (2003). Regional effects of terrorism on tourism in three Mediterranean countries. Journal of Conflict Resolution, 47(5), 621-641. https:// doi.org/10.2307/3176222

Evering ham, P. y Chassagne, N. (2020). Post COVID-19 ecological and social reset: moving away from capitalist growth models towards tourism as Buen Vivir. Tourism Geographies, 1-12. https://doi.org/10.1080/14616688.2020.1762119

Franklin, A. (2007). The problem with tourism theory. En I. Ateljevic, A. Pritchard y N. Morgan (Eds.), The critical turn in tourism studies (pp. 131-148). Elsevier.

Freire-Medeiros, B. (2014). Touring poverty. Routledge.

Gaffney, C. y Eeckels, B. (2020). COVID-19 and tourism risk in the Americas. Journal of Latin American Geography, 19(3), 308-313. https://doi.org/10.1353/ lag.2020.0054

Gallego, I. y Font, X. (2020). Changes in air passenger demand as a result of the COVID-19 crisis: using Big Data to inform tourism policy. Journal of Sustainable Tourism, 1-20. https://doi.org/10.1080/09669582.2020.1773476

Gössling, S., Scott, D. y Hall, C. M. (2020). Pandemics, tourism and global change: a rapid assessment of COVID-19. Journal of Sustainable Tourism, 1-20. https:// doi.org/10.1080/09669582.2020.1758708

Hall, C. Williams, M. y Lew, A. (2004). Tourism: conceptualizations, institutions, and issues. En A. Lew, M. Hall y A. Williams (Eds.), A companion to tourism (pp. 3-21). Blackwell Publishing. 
Higgins-Desbiolles, F. (2020a). Socializing tourism for social and ecological justice after COVID-19. Tourism Geographies, 1-14. https://doi.org/10.1080/146166 88.2020.1757748

Higgins-Desbiolles, F. (2020b). The "war over tourism": challenges to sustainable tourism in the tourism academy after COVID-19. Journal of Sustainable Tourism, 1-19. https://doi.org/10.1080/09669582.2020.1803334

Innerarity, D. (2017). Ethics of hospitality. Taylor \& Francis.

Korstanje, M. E. (2012). Reconsidering cultural tourism: an anthropologist's perspective. Journal of Heritage Tourism, 7(2), 179-184. https://doi.or$\mathrm{g} / 10.1080 / 1743873 X .2011 .639883$

Korstanje, M. E. (2018). Mobilities paradox: a critical analysis. Edward Elgar.

Korstanje, M. E. (2020a). El COVID-19 y la guerra invisible: ¿Es el fin de la hospitalidad? Rosa dos ventos - Turismo e Hospitalidade, 12(3), 1-9. http://www.ucs.br/ etc/revistas/index.php/rosadosventos/article/view/8420/pdf

Korstanje, M. E. (2020b). El turismo en un mundo incierto: desafíos para el siglo XXI en un contexto post COVID-19. Anais Brasileiros de Estudos Turísticos-ABET, 10(1, 2 у 3), 1-11. https://doi.org/10.34019/2238-2925.2020.v10.31397

Korstanje, M. E. y Clayton, A. (2012). Tourism and terrorism: conflicts and commonalities. Worldwide Hospitality and Tourism Themes, 4(1), 8-25. https://doi. org/10.1108/17554211211198552

Korstanje, M. E. y Olsen, D. H. (2011). The discourse of risk in horror movies post 9/11: hospitality and hostility in perspective. International Journal of Tourism Anthropology, 1(3-4), 304-317. https://doi.org/10.1504/IJTA.2011.043712

Korstanje, M. E. y Tarlow, P. (2012). Being lost: tourism, risk and vulnerability in the post-9/11entertainment industry. Journal of Tourism and Cultural Change, 10(1), 22-33. https://doi.org/10.1080/14766825.2011.639455

Lane, B. (1994). What is rural tourism? Journal of Sustainable Tourism, 2(1-2), 7-21. https://doi.org/10.1080/09669589409510680

Lash, S. M. y Urry, J. (1993). Economies of signs and space (Vol. 26). Sage. 
MacCannell, D. (1976). The tourist: a new theory of the leisure class. University of California Press.

MacCannell, D. (1992). Empty meeting grounds: The tourist papers. Psychology Press.

Mair, H., Reid, D. y George, W. (2005). Globalization, rural tourism and community power. En D. Hall, I. Kirkpatrick y M. Mitchell (Eds.), Rural tourism and sustainable business (pp. 165-179). Clevendon, Channel View.

Marques, L. y Borba, C. (2017). Co-creating the city: digital technology and creative tourism. Tourism Management Perspectives, 24, 86-93. https://doi.org/10.1016/j.tmp.2017.07.007

McKercher, B. y Chon, K. (2004). The over-reaction to SARS and the collapse of Asian tourism. Annals of Tourism Research, 31(3), 716-719. https://doi.org/10.1016/ S0160-7383(04)00028-3

Mitchell, M. y Hall, D. (2005). Rural tourism as sustainable business: key themes and issues. En D. Hall, I. Kirkpatrick y M. Mitchell (Eds.), Rural tourism and sustainable business (pp. 3-14). Clevendon, Channel View.

Monterrubio, J. C. (2010). Short-term economic impacts of influenza AH1N1 and government reaction on the Mexican tourism industry: an analysis of the media. International Journal of Tourism Policy, 3(1), 1-15. https://doi.org/ 10.1504/IJTP.2010.031599

Morrow, J. y Shields, R. (2019). Paul Virilio: clinical theory. Media Theory, 3(2), 179188. https://www.researchgate.net/publication/339391250_Paul_Virilio_Clinical_Theory

Nepal, S. K. (2020). Travel and tourism after COVID-19-business as usual or opportunity to reset? Tourism Geographies, 1-5. https://doi.org/10.1080/14616688 .2020 .1760926

Novelli, M., Burgess, L. G., Jones, A. y Ritchie, B. W. (2018). 'No Ebola... still doomed'The Ebola-induced tourism crisis. Annals of Tourism Research, 70, 76-87. https://doi.org/10.1016/j.annals.2018.03.006

Nylander, M. y Hall, D. (2005). Rural tourism policy: european perspectives. En D. Hall, I. Kirkpatrick y M. Mitchell (Eds.), Rural tourism and sustainable business (pp. 17-40). Clevendon, Channel View. 
Palmer, C. y Lester, J. A. (2007). Stalking the cannibals: photographic behaviour on the Sepik River. Tourist Studies, 7(1), 83-106. https://doi. org/10.1177/1468797607079806

Pratt, M. L. (2007). Imperial eyes: travel writing and transculturation. Routledge.

Richards, G. (2011). Creativity and tourism: the state of the art. Annals of Tourism Research, 38(4), 1225-1253. https://doi.org/10.1016/j.annals.2011.07.008

Richards, G. y Raymond, C. (2000). Creative tourism. ATLAS news, 23(8), 16-20. https://www.researchgate.net/publication/254822440_Creative_Tourism

Romagosa, F. (2020). The COVID-19 crisis: opportunities for sustainable and proximity tourism. Tourism Geographies, 1-5. https://doi.org/10.1080/14616688.2 020.1763447

Saha, S. y Yap, G. (2014). The moderation effects of political instability and terrorism on tourism development: a cross-country panel analysis. Journal of Travel Research, 53(4), 509-521. https://doi.org/10.1177/0047287513496472

Schlüter, R. G. (2003). El Turismo en Argentina: del balneario al campo. Centro de Investigaciones y Estudios Turísticos.

Sharpley, R. (2002). Rural tourism and the challenge of tourism diversification: the case of Cyprus. Tourism Management, 23(3), 233-244. https://doi.org/10.1016/ S0261-5177(01)00078-4

Sheller, M. (2020). Reconstructing tourism in the Caribbean: connecting pandemic recovery, climate resilience and sustainable tourism through mobility justice. Journal of Sustainable Tourism, 1-14. https://doi.org/10.1080/09669582.2 020.1791141

Sigala, M. (2020). Tourism and COVID-19: impacts and implications for advancing and resetting industry and research. Journal of Business Research. https://doi. org/10.1016/j.jbusres.2020.06.015

Solarin, S. A. (2015). September 11 attacks, H1N1 influenza, global financial crisis and tourist arrivals in Sarawak. Anatolia, 26(2), 298-300. https://doi.org/10.10 80/13032917.2014.991933 
Stankov, U., Filimonau, V. y Vujičić, M. D. (2020). A mindful shift: an opportunity for mindfulness-driven tourism in a post-pandemic world. Tourism Geographies, 1-10. https://doi.org/10.1080/14616688.2020.1768432

Sunstein, C. R. (2005). Laws of fear: beyond the precautionary principle (Vol. 6). Cambridge University Press.

Tan, S. K., Luh, D. B. y Kung, S. F. (2014). A taxonomy of creative tourists in creative tourism. Tourism Management, 42, 248-259. https://doi.org/10.1016/j.tourman.2013.11.008

Tarlow, P. (2014). Tourism security: strategies for effectively managing travel risk and safety. Elsevier.

Timothy, D. (2005) Rural tourism business: a North American overview. En D. Hall, I. Kirkpatrick y M. Mitchell (Eds.), Rural tourism and sustainable business (pp-4162). Channel View.

Tzanelli, R. (2004). Constructing the 'cinematic tourist': the 'sign industry' of The Lord of the Rings. Tourist Studies, 4(1), 21-42. https://doi. org/10.1177/1468797604053077

Tzanelli, R. (2008). Anthropological encounters. En Nation-building and identity in Europe (pp. 71-99). Palgrave Macmillan.

Tzanelli, R. (2013). Struggling with the Other: embodied styles as tourist articulation. En Olympic Ceremonialism and The Performance of National Character: From London 2012 to Rio 2016 (pp. 96-117). Palgrave Macmillan.

Wen, J., Wang, W., Kozak, M., Liu, X. y Hou, H. (2020). Many brains are better than one: the importance of interdisciplinary studies on COVID-19 in and beyond tourism. Tourism Recreation Research, 1-4. https://doi.org/10.1080/02508281 .2020 .1761120

Wilson, S., Fesenmaier, D. R., Fesenmaier, J. y Van Es, J. C. (2001). Factors for success in rural tourism development. Journal of Travel Research, 40(2), 132-138. https:// doi.org/ 10.1177/004728750104000203

Yuan, M. (2005). After September 11 th: determining its impacts on rural Canadians' travel to the US. E-review of Tourism Research, 3(5), 103-108. http://ertr.tamu. edu/pdfs/a-91.pdf 